\title{
SYEKH MOHAMMAD ARSYAD THAWIL 1851-1934: PERJUMPAAN ULAMA BANTEN DENGAN JEMAAT KRISTEN MINAHASA
}

\author{
SYEKH MOHAMMAD ARSYAD THAWIL 1851-1934: \\ THE ENCOUNTER OF BANTEN 'ULAMA' WITH MINAHASAN CHRISTIANS
}

\author{
Almunawar Bin Rusli \\ Institut Agama Islam Negeri Manado \\ Jalan Dr. S.H. Sarundajang Kompleks Ring Road I Manado \\ Email: almunauwar.binrusli@iain-manado.ac.id
}

Naskah diterima tanggal 6 April 2020, Naskah direvisi tanggal 29 Mei 2020, Naskah disetujui tanggal 9 Juni 2020

\begin{abstract}
Abstrak
Ulama dapat dilihat sebagai mereka yang memiliki karya intelektual dan melibatkan diri dalam memberikan arahan dan bimbingan kepada masyarakat mereka saat berafiliasi atau memiliki hubungan dengan lembaga tertentu. Pertarungan ulama dalam sejarah kolonialisme Indonesia terjadi melalui kesadaran eskatologis, tindakan etis dan refleksi mistis. Syekh Mohammad Arsyad Thawil adalah salah satu ulama penting pada kasus ini. Dia lahir di Tanara, Banten 1851 dan meninggal di Lawangirung, Manado 1934. Syeikh Mohammad Arsyad Thawil belajar Islam pada tiga orang guru: Syekh Abdul Gani Bima, Syekh Ahmad Zaini Dahlan dan Syekh Nawawi Al-Bantani. Dia tinggal di Mekkah dari 1868-1873 dan terlibat dalam pemberontakan petani Banten 9-13 Juli 1888. Pertama, sejak 1808 Banten jatuh di bawah kekuasaan Belanda. Birokrasi kolonial menghancurkan birokrasi tradisional. Kedua, dihapuskan tanah pusaka, penarikan pajak, dan kerja paksa. Ketiga, kemunculan gerakan sufi, pesantren dan kelompok haji yang membentuk ideologi Pan-Islam. Ketika diasingkan di Airmadidi, Minahasa 1888, dia menikah dengan perempuan Kristen bernama Magdalena Runtu. Pada 1912, Syekh Mohammad Arsyad Thawil menjadi Penghoeloe Landraad serta guru agama Islam di Minahasa. Pada 1923, Syekh Mohammad Arsyad Thawil menjadi Adviseur Hoofd Bestuur Locaal Sarekat Islam Manado. Salah satu muridnya di Manado adalah Habib Alwi Bin Abdurrahman Bin Smith. Pergerakan dakwah Syeikh Mohammad Arsyad Thawil dibantu Kapiten Tan Tjin Bie. Sehingga, Islam dan Tionghoa memiliki relasi pengetahuan dan kuasa karena unsur kerjasama niaga dan memori niaga.
\end{abstract}

Kata Kunci: syekh mohammad arsyad thawil, banten, minahasa

\begin{abstract}
the Ulama can be discerned as those who have an intellectual work and engange themselves in giving direction and guidance to their society while being affiliated or having relations with certain institution. The fight of 'Ulama' in the history of Indonesian colonialism took place through eschatological awareness, ethical action and mystical reflection. Syeikh Mohammad Arsyad Thawil is one of the important Ulama in this case. He was born in Tanara, Banten 1851 and died in Lawangirung, Manado 1934. Syekh Mohammad Arsyad Thawil studied Islam on three teachers: Syeikh Abdul Gani Bima, Syeikh Ahmad Zaini Dahlan and Syeikh Nawawi Al-Bantani. He lived in Mekkah from 1868-1873 and was involved in the Banten peasant uprising 9-13 July 1888. First, since 1808 Banten fell under Dutch rule. Colonial bureaucracy destroys traditional bureaucracy. Second, abolition of inheritance, tax collection and forced labor. Third, the raises of sufi movements, pesantren and pilgrimage groups that formed the Pan-Islamic ideology. When exiled at Airmadidi, Minahasa 1888, he married with Christian woman named Magdalena Runtu. In 1912, Syeikh Mohammad Arsyad Thawil became Penghoeloe Landraad and a teacher of Islamic religion in Minahasa. In 1923, Syeikh Mohammad Arsyad Thawil became Adviseur Hoofd Bestuur Locaal Sarekat Islam Manado. One of his students in Manado was Habib Alwi Bin Abdurrahman Bin Smith. The da'wah movement of Syeikh Mohammad Arsyad Thawil was supported by Kapiten Tan Tjin Bie. Thus, Islam and Tionghoa have relations of knowledge and power because of cooperation of commerce and memory of commerce.
\end{abstract}

Keywords: syekh mohammad arsyad thawil, banten, minahasa 


\section{PENDAHULUAN}

$\mathrm{M}$ asa pemerintahan Sultan Ageng Tirtayasa (1651-1683) adalah zaman keemasan Kerajaan Banten. Dia memiliki suatu armada yang mengesankan yang dibangun menurut model Eropa. Pada masa ini, Banten diperkirakan mengalami pertumbuhan jumlah penduduk dari sekitar 150.000 jiwa menjadi sekitar 200.000 jiwa diakhirinya kekuasaannya (Ricklefs,2005:180-181). Banten dulu adalah pelabuhan yang bebas dan terbuka bagi perdagangan semua bangsa. Namun, perdagangan itu dimonopoli Belanda ketika Sultan Agung berkuasa pada 1683. Mereka mendirikan Fort Spielwijk untuk menghalangi masuknya pedagang lain. Usaha ini menimbulkan kekecewaan besar dan menambah kebencian masyarakat lokal. Walaupun begitu, rantai perbudakan kolonial justru semakin kuat dan pada 1742 rakyat Banten dikalahkan. Perdagangan lada adalah yang paling penting di sini, daerah Lampung termasuk pembayar upeti terbesar kepada Banten (Thorn, 1815:282-283).

Setelah blokade atas pelabuhan Banten ditaklukkan, orang Belanda berhasil mengontrol laut Jawa. Armada Inggris pun diserbu di beberapa titik dan tujuh kapal tertawan. Yang lain mundur ke India. Sehingga, Raja James memprotes keras kepada duta besar Belanda di London. Karena ini merupakan peristiwa berdarah dalam sejarah persaingan komersial yang tidak mengenal belas kasihan (Vlekke, 2016:132).

Sistem pemerintahan feodal sangat menindas rakyat. Pemimpin pribumi pun menjalankan sistem yang sama sehingga tidak ada pengawasan. Kerja paksa yang dilakukan orang-orang Banten dalam membangun markas dan jalan membuat mereka harus membiarkan tanah-tanah pusaka dirampas, mereka mengungsi ke hutan dan memulai perlawanan. Perpindahan penduduk sampai perlakuan kasar terhadap orang Banten menyebabkan kerajaan Banten hancur. Mereka sangat membenci kolonialisme dan tidak percaya pada orang Eropa. Semangat ini terus dikobarkan oleh para pemuka agama (Vlekke, 2016:285-286).
Peristiwa dari abad ke-17 di atas terus berlanjut, hingga memasuki abad ke-19. Syekh Mohammad Arsyad Thawil (18511934) termasuk salah seorang dari para pemuka agama tersebut. Studi Mansurnoor menjelaskan, peran ulama senantiasa berakar kuat dalam kehidupan keagamaan dan sosiopolitik umat Islam. Noor merujuk kepada karakter dinamis keberadaan ulama dan menunjukkan, bahwa mereka menyadari posisinya yang strategis dalam struktur desa yang membuat mereka beradaptasi pada berbagai situasi baru melalui diskursus bahasa Islam kontemporer yang bisa diterima secara luas (Burhanudin,2012:4-5).

Pocock merumuskan ekspresi idepemikiran agama saling berhubungan sekaligus mempengaruhi dengan realitas politik, ekonomi dan budaya. Reformulasi Islam oleh ulama yang berlangsung terusmenerus menandai keterlibatan mereka dalam pembentukan humanisme sipil (civic humanism) dalam politik Indonesia. Dengan memobilisasi tradisi, ulama secara sadar berpartisipasi dalam diskusi tersebut dengan berkonsentrasi pada persoalan-persoalan publik masyarakat Indonesia (Burhanudin, 2012:9-10).

Studi ini menekankan pada sejarah pemikiran keagamaan dan pergerakan sosial Syekh Mohammad Arsyad Thawil yang relatif terabaikan dalam kajian-kajian kesejarahan terdahulu. Saya berargumen, periode kolonial mempunyai arti penting bagi eksistensi ulama Indonesia. Periode ini, faktanya mampu mendorong para ulama untuk membuat kelompok khusus yang berbeda dari penghulu, karena mereka dipandang sebagai pegawai kolonial yang kurang memiliki militansi terhadap ajaran-ajaran dasar Islam. Mereka cenderung memanfaatkan bahasa agama yang eksklusif dan sikap sosial yang inklusif.

Studi ini dimaksudkan untuk memberikan penjelasan historis terkait tiga hal pokok. Pertama; apa doktrin pemikiran Islam yang dipelajari Syekh Mohammad Arsyad Thawil di Mekkah. Kedua; mengapa doktrin tersebut menimbulkan revolusi Banten. Ketiga; mengapa relasi pengetahuan dan kuasa Syekh Mohammad Arsyad Thawil 
dengan Kapitein Tan Tjin bie, saat berada di Minahasa dapat terjalin harmonis.

\section{TINJAUAN PUSTAKA}

Studi ini menggunakan istilah perjumpaan (encounter) yang sesuai dengan etika Levinasian. Bagi Levinas, perjumpaan dengan orang lain ini adalah momen paling primordial di dalam kehidupan. Selain kehadirannya menuntut tanggung jawab pribadi, kehadiran orang lain juga membuat pribadi menemukan identitas dan keunikan. Bertanggung jawa membuat pribadi menemukan ke-aku-an diri. Levinas memahami bahwa perjumpaan dengan orang lain memiliki pengalaman transendensi. Kemuliaan dari Yang-Tak-Terhingga. Tanggung jawab dalam proses perjumpaan bersifat relasi asimetri bukan resiprositas. Levinas tidak melihat tanggung jawab dari dua arah. Hakekat pribadi adalah bertanggung jawab tanpa mengharapkan kembali (Fawaid, 2013:132).

Bagi Levinas, orang lain adalah pembuka horizon keberadaan manusia. Levinas menawarkan perjumpaan etis. Perjumpaan yang dimaksud adalah perjumpaan dengan orang lain. Status ontologis dari orang lain adalah memiliki kesatuan fisik-psikis secara universal sekaligus partikular. Orang lain termasuk pribadi yang berhak atas keluhuran martabatnya. Orang lain juga bisa berarti mereka yang hendak kita rengkuh seutuhnya, mereka yang kita bayangkan sebagai objek yang dapat kita pahami alteritasnya. Bagi Levinas, orang lain selalu ada di luar inteligibelitas ego. Orang lain adalah sesuatu yang eksterior, transenden, yang melampaui kesadaran dan dunia ego (Fawaid, 2013 :133).

Dengan demikian, perjumpaan dan mengandaikan adanya dua pihak yang setara atau sederajat berjumpa secara seimbang baik dalam arti fisikal dan konseptual. Manusia selalu berjumpa dalam totalitasnya sebagai individu maupun kelompok. Di dalam perjumpaan akan muncul integrasi juga dikotomi pemikiran dan perbuatan. Maka dialog eksistensial adalah etika yang mesti ditempuh.

Selanjutnya, Ulama berawal dari Alim yang didefiniskan sebagai manusia yang memiliki keahlian dalam pengetahuan dan pengalaman Islam. Karakteristik utama dari Ulama adalah bersifat religius-sosialistik (Niam, 2010:293). Ulama dalam studi ini menggunakan paradigma Weberian yakni charismatic leader. Weber menggunakan istilah karisma untuk menjelaskan bahwa pemimpin diberkahi oleh kemampuan metafisika. Karisma adalah daya tarik seseorang yang tidak bisa dibeli dengan apapun karena substansinya dari Tuhan yang mutlak. Otoritas karismatik merupakan rezim yang paling bertahan lama karena pemimpin dianggap tidak dapat salah dan tindakan apa pun terhadapnya akan dianggap sebagai kejahatan terhadap pengikutnya. Para pemimpin karismatik akhirnya mengembangkan kultus kepribadian yang sering kali bukan karena perbuatan mereka sendiri. Otoritas pemimpin karismatik dalam konteks agama membutuhkan keyakinan yang militan bahwa pemimpin itu telah menyatu dengan Allah. Jika keyakinan ini hancur, maka otoritas pemimpin karismatik dapat memudar dengan cepat. Weber melihat otoritas karismatik menciptakan intersubjektivitas (Weber, 2012:38-39).

Terakhir, Minahasa adalah sebuah daerah di Sulawesi Utara. Istilah Minahasa, pertama kali muncul di catatan Belanda pada tahun 1789 dan hanya mengacu pada dewan kepala desa (landraad). Baru sekitar tahun 1820 istilah tersebut mengandung arti geografis atau etnis saat digunakan dalam masa kolonial, landstreek van Manado. Asal etimologis kata Minahasa umumnya merujuk pada sumber linguistik yaitu mina-esa, maesa, maha-esa. Semua mengacu pada penyatuan kelompok-kelompok yang sebelumnya terpisah secara kultural dan linguistik, pada proses menjadi satu (Weichart,2004:61)

Hal ini terjadi dalam masa kolonial Belanda. Secara administrasi, mereka berusaha keras untuk mendukung dan mempercepat proses penyatuan tersebut demi kepentingan pengusaha dan misionaris. Mereka ingin menyatukan semua suku agar dapat membentuk stabilitas sosial. Stabilitas sosial dapat tercipta jika adanya loyalitas komunal dimana masyarakat lokal tetap dijadikan bagian penting dalam merumuskan kebijakan-kebijakan pemerintahan di Minahasa. (Weichart, 2004:62). 
Dampak eksternal yang paling kuat dalam proses pembentukan identitas Minahasa datang dari Gereja Protest an seiring dengan usaha mereka untuk menyebarluaskan agama Kristen. Saat ini, mayoritas penduduk Minahasa beragama Kristen dan di antara berbagai kongregasi yang ada, GMIM (Gereja Masehi Injili di Minahasa) adalah yang terbesar. Konstruksi identitas, baik di tingkat individu maupun kolektif, adalah proses dialektik antara mengenali kesamaan dan perbedaan, dan sebagai akibatnya, antara inklusi dan eksklusi (Weichart,2004:62). Agama telah memainkan peran yang besar dalam proses ini karena Minahasa menjadi benteng Kristen di negara yang didominasi Muslim.

Mayoritas penduduk Minahasa adalah Kristen Protestan dengan populasi sekitar 795.284 jiwa. Minahasa sendiri berhasil mengalami proses Kristenisasi radikal sejak hadirnya misionaris Jerman yaitu J.G. Schwarz dan J.F. Riedel (1831 hingga awal 1860-an). Pekerjaan mereka membawa banyak berkah. Ribuan orang Minahasa meminta dibaptis (de Jonge,2008:419).

\section{METODE PENELITIAN}

Sejarah didefinisikan sebagai suatu kajian sistematis berdasarkan prinsip dan at uran filosofis untuk menghimpun dokumen kesejarahan. Dokumen itu kemudian dinilai dan diuji secara kritis agar ditemukan suatu sintesis. Gottschalk mendefinisikan metode sejarah sebagai suatu proses ilmiah untuk menelusuri konsistensi perkataan dan tindakan manusia secara kritis serta memahami relasi objektif antara keduanya (Gottschalk,1985: 32).

Studi ini menggunakan metode penelitian sejarah yang meliputi proses pengumpulan sumber (heuristik), kritik sumber, interpretasi, dan historiografi (Langlois \& Seignobos,2015:25). Dalam proses heuristik, penulis menggunakan data primer dan sekunder. Pada sumber primer, penulis menggunakan sumber dari arsip dokumen keluarga, situs makam dan masjid Syeikh Mohammad Arsyad Thawil di Manado. Pada sumber sekunder, penulis menggunakan literatur kesejarahan mutakhir yang relevan dengan studi ini. Literatur tersebut terkonsentrasi pada wacana relasi Ulama dengan realitas politik dan keagamaan di Indonesia. Semua informasi tersebut kemudian dianalisis dengan pendekatan multikausal berdasarkan prinsip keterhubungan dan keterpengaruhan antara masing-masing fokus kajian.

Setelah itu, penulis melakukan kritik sumber (verifikasi data) secara eksternal (orisinalitas) dan internal (kredibilitas). Kritik eksternal dilakukan dengan menguji keaslian bahan dan bentuk sumber dokumen, umur dan asal dokumen, aktor penyusun dokumen dan waktu penyusunan dokumen. Kemudian dalam kritik intern penulis melakukan pengujian data kesejarahan melalui suatu kesaksian keluarga sekaligus murid-murid lintas generasi dari Syekh Mohammad Arsyad Thawil di Manado. Proses interpretasi data dilakukan melalui dua cara yaitu analisis dan sintesis antar data kesejarahan secara konsisten guna menjelaskan fakta-fakta sosial. Pada proses historiografi, penulis menyajikan hasil kajian historis-deskriptif dengan merujuk pada data yang bersifat kronologis, konsisten dan terakhir penulis mencoba membangun asumsi at as data kesejarahan.

\section{Mekkah: Benteng Islam Kharismatik}

Syekh Mohammad Arsyad Thawil lahir di Tanara, Banten, 1851. Imam As'ad adalah ayah, sekaligus sumber inspirasi awal baginya untuk memperdalam dimensi keislaman di pesantren. Pada 1867, S.M. Arsyad Thawil berangkat ke Bima untuk berguru kepada Syekh Abdul Gani. Namun, mereka berdua justru bertemu di Tanjung Perak, Surabaya. Syekh Abdul Gani kemudian menetap selama 1 tahun di Surabaya, dan menerimanya sebagai murid khusus, karena ia memiliki hubungan erat dengan Imam As'ad. Sekitar 1868, Syekh Abdul Gani berangkat ke Mekkah bersama S.M. Arsyad Thawil atas izin dari ayahnya di Tanjuk Periuk. Kapal mereka melalui Singapura, Kolombo, Malaka, Aden, Jeddah lalu sampai Mekkah selama 6 bulan. Dia tinggal di Mekkah selama 5 tahun dari 1868 hingga 1873 (Effendi, 1983:2-18). 
Selama di Mekkah, S.M. Arsyad Thawil tetap berguru kepada Syekh Abdul Gani, ditambah dengan Syekh Ahmad Zaini Dahlan serta Syekh Nawawi Al-Bantani. Laffan menjelaskan, Syekh Abdul Gani Bima dikenal sebagai murid Abd al-Samad alFalimbani. Dia mengkhususkan diri dalam pengajaran fikih di Malaya dan masih dikenang dengan penuh cinta pada 1880-an, nyaris sebagai wali dan guru terkemuka bagi seluruh generasi cendekiawan Jawi (Laffan, 2011:54-55).

Di sisi lain, Syekh Ahmad Zaini Dahlan adalah mufti agung bermazhab Syafi' $i$ di Mekkah sejak 1870. Muhimmat al-Nafais fi Bayan Asilah al-Hadist merupakan kitab fatwanya yang menjadi rujukan wajib masyarakat muslim Jawa. Ia wafat pada 1886 (Burhani, 2016:50-51). Sedangkan peran sentral Syekh Nawawi Al-Bantani (18131897) di tengah ulama Jawi terletak pada aspek intelektualnya. Kitab-kitabnya menjadi sumber pembentukan dikursus Islam berbasis pesantren seperti Lubab al-Bayan (1884), Dzariyat al-Yaqin (1886), Suluk al-Jadah (1883), dan Sulam al-Munajah (1884). Unsur sufistik dan ikatan budaya tradisional pedesaan membuat santri patuh padanya (Burhanudin, 2012:113-123).

Merujuk pada variasi keilmuan dari tiga guru di atas, dapat dikatakan, bahwa Syekh Mohammad Arsyad Thawil memutuskan untuk mendalami ilmu tauhid kepada Syekh Nawawi Al-Bantani, ilmu syariah kepada Syekh Abdul Gani, dan ilmu ibadah kepada Syekh Ahmad Zaini Dahlan. Tiga dimensi ini masing-masing saling melengkapi dan tidak dapat dipisahkan dari perhatian Syekh Mohammad Arsyad Thawil. Sangat dimungkinkan, proses pembelajaran di Mekkah tersebut berlangung di dalam rumah dan Masjid menggunakan metode sorogan dan bandongan secara intensif.

Saat di Mekkah, Syekh Mohammad Arsyad Thawil sempat tinggal bersama Syekh Nawawi Al-Bantani di rumahnya, di Perkampungan Syi'ib Ali, dekat Masjid alHaram (Nasution, 1992:176-177). Al-Nawawi memang telah menetap di Mekkah untuk selamanya sejak 1855 hingga wafatnya 1897 (Azra, 2013:395). Kemungkinan besar, alNawawi membuat sistem sorogan, yakni pembelajaran Islam bercorak personal kepada
S.M. Arsyad Thawil di tempat sunyi. Sehingga, ia dapat mengawasi dan menilai secara langsung kondisi fisik dan mentalnya. Sedangkan S.M. Aryad Thawil juga mengembangkan ilmu keislaman di Masjid bersama Syekh Abdul Gani serta Syekh Ahmad Zaini Dahlan. Masjid adalah manifestasi universalisme dari sistem pembelajaran Islam tradisional. Tradisi kaum Muslim sejak masa Muhammad ialah cenderung menjadikan Masjid sebagai pusat pertemuan politik, ekonomi, dan budaya. Pada bagian ini, digunakan sistem bandongan, yang berarti pembelajaran Islam bercorak komunal. Semua murid mendengar dan mencatat ide-ide pokok ilmu syariah dan ibadah yang disampaikan guru mereka, lalu dihubungkan dengan realitas di negeri masing-masing.

Kehadiran Syekh Mohammad Arsyad Thawil di Mekkah ikut diperkuat oleh keterangan Snouck Hurgronje. Snouck mengaku telah berinteraksi langsung dengan beberapa ulama Jawi lainnya, yang informasi tersebut diterimanya dari Aboe Bakar Djajadiningrat pada 1887. Mereka adalah Nawawi, Marzuq, Isma'il, Abd al-Karim, Arshad bin Alwan, dan Arsyad bin As'ad. Lebih jauh, Banten secara konsisten merupakan daerah yang menjadi sumber jamaah haji terbesar. Sebanyak 25 orang guru Banten bekerja di Mekkah, karena reputasi keilmuannya. Di antaranya, dua perempuan (Laffan, 2003:62-63).

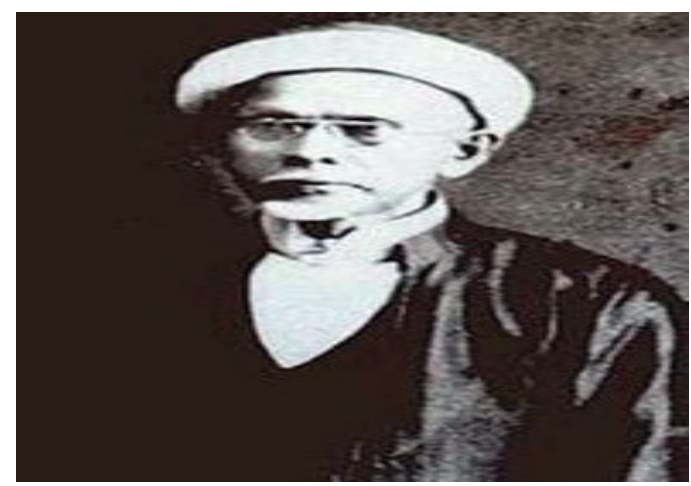

(Syekh Mohammad Arsyad Thawil 1851-1934. Sumber: Effendi 1983)

Gelar Syekh diperoleh Mohammad Arsyad Thawil dari Raja Abdul Muthalib sejak bertugas mengurus proses ritual haji yang jamaahnya paling banyak datang dari Indonesia. Di Mekkah, Syekh Mohammad Arsyad Thawil menikahi perempuan setempat bernama Siti Chadidjah. Mereka memiliki 
anak, yaitu As'ad. As'ad menikahi Rachmah (Mekkah) dan Aisiyah (Banten). Keturunan dari Rachmah ialah Musthafa, Amriyah, Husen dan Arsyad. Sedangkan dari Aisiyah ialah Oemar (Effendi,1983:24-25).

\section{Revolusi Banten: Pertunjukan Jihad Rakyat}

Dimensi tauhid, syariah, dan ibadah yang dipelajari secara serius dan konsisten oleh Syekh Mohammad Arsyad Thawil selama dia tinggal di Mekkah, telah sukses melahirkan tiga doktrin utama Islam, yaitu monoteime, moralisme, dan sosialisme. Selama di Banten, S.M. Arsyad Thawil selalu menjumpai Haji Wasid dan Haji Tubagus Ismail untuk membicarakan persoalan Islam dan kolonialisme, yang kemudian berujung pada tragedi Geger Cilegon (Effendi, 1983:1148). Pada 9 Juli malam, 1888, Cilegon diduduki sekitar 100 orang pemberontak. Mereka bergerak dari rumah Haji Ishak. Kekerasan, pembunuhan, penyiksaan, dan penjarahan terjadi. Penguasa Belanda dan pejabat-pejabat pribumi bentukan kolonial menjadi sasaran kemarahan massa. Pada 13 Juli 1888, pemberontakan itu berhasil dipadamkan. Serdadu Belanda ditempatkan di Cilegon, pemimpin-pemimpin pemberontakan dikejar, ditahan dan diadili (Kuntowijoyo,2008:43).

Haji Wasid, Haji Tubagus Ismail, Haji Abdul Gani, dan Haji Usman adalag empat pemimpin utama dalam pemberontakan ini. Sasaran pemberontakan adalah penjara untuk membebaskan tahanan, kepatihan, dan kantor asisten residen. Pejuang Geger Cilegon yang ditahan Belanda berjumlah sekitar 204 orang. 94 orang dibuang ke luar Banten, 89 orang dihukum kerja paksa, dan 11 orang dihukum gantung. Mereka adalah Samidin, Taslim, Kamidin, Haji Mohammad Achya, Haji Moechid, Dulmanan, Jakaria, Haji Hamimi, Dengi, Oyong dan Kasar (Effendi, 1983:5152).

Selain itu, Haji Jafar, Haji Arja, Haji Saban, Akhmad, Yahya, dan Saliman berhasil meloloskan diri. Sedangkan Haji Abdul Karim dan Haji Marjuki, dikejar pihak Belanda sampai ke Mekkah. Posisi Syekh Mohammad Arsyad Thawil dalam revolusi Banten termasuk kategori orang buangan. Sangat dimungkinkan, semangat jihadnya ditularkan oleh Syekh Nawawi Al-Bantani ketika di Mekkah dan mereka juga lahir di tanah yang sama: Tanara. Dalam catatan sejarah, kemasyhuran Nawawi dinilai pihak Belanda sebagai suatu hal yang membahayakan dan mengganggu stabilitas politik. Pemerintah kolonial sampai melakukan pengawasan ketat terhadap seluruh aktivitas Nawawi di tanah air (Nasution, 1992:175). Oleh sebab itu, murid terdekatnya harus disingkirkan dari masyarakat Banten. Snouck mencatat, delapan kali rapat persiapan pemberontakan dilakukan. Dan enam kali Syekh Mohammad Arsyad Thawil menghadirinya. Asumsi sementara adalah, Syekh Mohammad Arsyad Thawil adalah konseptor pemberontakan. Melihat tingginya keterlibat an kelompok Haji ini, Raffles mencatat :

"Setiap orang Arab dari Mekkah, begitu pula orang
Jawa yang kembali menunaikan ibadah haji di sana,
diterima sebagai orang suci di Jawa dan sikap cepat
percaya dari kalangan orang awam sudah
sedemikian rupa sehingga mereka sangat sering
menghubungkan berbagai kekuatan adialami kepada
pribadi-pribadi yang demikian. Karenanya, tidak
sulit bagi mereka membangkitkan Negeri untuk
memberontak. Para ulama Muhammedan hampir
tanpa terkecuali ditemukan paling aktif dalam setiap
pemberontakan. Banyak dari mereka, umumnya
keturunan campuran Arab dan orang pribumi,
pindah dari satu negeri ke negeri lain di pulau-pulau
bagian Timur dan umumnya karena intrik-intrik dan
akibat desakan merekalah para pemimpin pribumi
terhasut untuk menyerang atau membunuh orang-
orang Eropa sebagai orang kafir dan pengacau."
(Steenbrink, 2017:117-118).

Rooff menemukan, gelar Haji dapat merubah persepsi manusia mengenai Islam, kaum muslimin, imperatif-imperatif dan kekuatan-kekuatannya. Dengan demikian, mereka menjadi milik komunit as muslim yang luas (global), nasional dan lokal. Sehingga, mereka kembali ke masyarakat asalnya (Martin, 2002:120-121). Bagi penulis, gelar ini berimplikasi pada proses penciptaan ideologi, penguatan identitas serta penyebarluasan revolusi.

Studi mutakhir Sartono Kartodirdjo menunjukkan bahwa revolusi Banten disebabkan tiga faktor : yaitu sosial-politik, sosial-ekonomi, dan sosial-kultural. Pertama, semakin renggangnya jarak sosial antara 
petani, elite pedesaan, elite agama, sekaligus pejabat kolonial bentukan Belanda. Sejak 1808, Banten jatuh di bawah kekuasaan Belanda. Birokrasi legal-rasional menggantikan birokrasi tradisional. Aristokrasi tradisional yang diasingkan dari kekuasaan itu bergabung dengan petani, elite pedesaan, dan elite agama. Mereka membuat keresahan sosial secara endemis sepanjang abad 19. Keinginan mengembalikan kekuasaan ke tangan aristokrasi tradisional terlihat dalam peristiwa Sabidin beberapa tahun menjelang 1888. Bagi aristokrat tradisional Banten, Sabidin dipandang sakti, karena anak dari Sultan Banten yang diasingkan. Ketika rakyat berbondongbondong menghadiri masjidnya setiap Jumat, pemerintah kolonial akan membatasinya, karena dia sosok yang menentang keras sistem feodalisme (Kuntowijoyo,2008:43).

Kedua, masuknya ekonomi uang dan tenaga kerja upahan ke tengah-tengah masyarakat Banten yang agraris. Dihapuskan tanah-tanah kerajaan dan pelayanan tenaga kerja untuk pejabat-pejabat kerajaan menimbulkan ketidakpuasan. Konflik atas hak-hak tanah terjadi. Negara menghapuskan banyak klaim atas tanah pusaka, penarikan pajak tanah, dan sementara itu kerja paksa yang berupa kerja desa dan kerja pemerintah berjalan terus. Beban petani semakin berat (Kuntowijoyo,2008:44).

Peristiwa ini sejalan dengan tesis Reid bahwa kunci pokok sistem sosial Asia Tenggara adalah kontrol terhadap manusia. Tanah tersedia berlimpah namun tidak dapat dikuasai. Masyarakat dipertautkan oleh ikatan-ikatan vertikal dan kewajiban antar manusia atas utang mereka. Sistem perbudakan di Asia Tenggara lebih didasarkan pada kerja wajib untuk kepentingan majikan. Sistem perhambaan yang merupakan bagian dari perbudakan muncul dari pola dasar lebih luas dan dalam situasi tertentu mengambil peran utama di bidang ekonomi dan politik. Mereka adalah komoditas sekaligus manusia, dieksploitasi tapi juga diyakini tetap setia, derajatnya rendah tapi bisa menjalin hubungan yang akrab (Reid, 2004:248-249).

Ketiga, bangkitnya kembali agama yang oleh otoritas kolonial dianggap sebagai kekuatan politik. Pada akhir abad 19, muncul persaudaraan-persaudaraan sufi, pesantren, dan kelompok haji. Pemerintah kolonial mencurigai adanya konspirasi antara elite agama dan petani. Mereka merasa terancam at as kehadiran kelompok Haji yang membawa arus militan dari ortodoksi agama dan terkontaminasi oleh cita-cita politik PanIslam (Kuntowijoyo, 2008:44). Tarekat Qadiriyah wa Naqsyabandiyah memainkan peran kunci dalam pemberontakan petani Banten pada tahun 1888. Banten diasosiasikan secara dekat dengan militansi Islam. Model tarekat ini menyediakan suatu jaringan komunikasi dan suatu mata rantai yang memungkinkan dilakukannya mobilisasi massa. Dalam konteks Banten, tarekat terhubung aktif dengan kebijakan raja, kekuatan magis dan legitimasi politik (Bruinessen, 2015:328-331).

Tarekat Syathariyyah yang dibawa Syaikh Abd Al-Muhyi ke Banten juga memegang pengaruh penting. Hal ini disebabkan akibat meningkatnya kontak antara Kesultanan Banten dan Timur Tengah sejak paruh pertama abad ke-17 (Azra, 2002:107-108). Al-Muhyi adalah murid Abd Al-Ra'uf Al-Sinkili.

Sebagai benteng Islam kharismatik, dapat dikatakan bahwa Mekkah telah berhasil memberikan indoktrinasi sekaligus inspirasi bagi golongan Syekh dan Haji untuk melakukan pertunjukan jihad rakyat di Banten. Keterhubungan aktif antara pemikiran agama di Mekkah dengan pergerakan di Indonesia (Banten) dalam argumentasi penulis diakibatkan oleh tiga faktor utama. Pertama; adanya kesadaran eskatologis. Kesadaran ini mengacu kepada pemahaman total terhadap kehidupan setelah kematian. Para ulama dan petani melihat Banten sedang dalam kondisi rusak parah dan dikendalikan para orang Kafir Eropa. Kesadaran ini melahirkan nalar bahwa kekerasan bukan sebagai tindakan agresi melainkan upaya penyelamatan dan penebusan dosa sosial. Mereka meyakini bahwa kematian yang diperoleh melalui proses jihad bisa mengantarkan mereka ke dalam syurga Allah SWT. Sehingga, mereka dapat menikmati kehidupan baru yang abadi, bebas dari kejahatan manusia.

Kedua; adanya tindakan etis. Ulama dan petani Banten sudah terbiasa berinteraksi berdasarkan aturan hukum Islam dan hukum 
adat. Kedua hukum tersebut saling menguatkan dan kemudian menjadi norma publik. Sehingga, dampak dari interaksi ini senantiasa mengacu kepada hati nurani individu sekaligus ikat an solidaritas komunal. Oleh sebab itu, dalam pandangan mereka, sistem kolonialisme Belanda merupakan bentuk kejahatan kemanusiaan yang dengan sadis membunuh kebebasan, keadilan dan rasa persaudaraan rakyat Banten yang ditindas.

Tindakan etis terungkap dalam hukum perjanjian yang dibuat oleh pihak Ulama dan petani di Banten yang pada dasarnya berisi tentang kesepakatan untuk saling membantu dalam soal politik, ekonomi hingga agama. Hukum perjanjian ini prinsipnya mengikat dan mewajibkan. Karena, mereka berpatokan pada kenyataan. Dalam konteks revolusi Banten atau Geger Cilegon ini, sangat mungkin tindakan etis di atas hanya dapat diketahui melalui kontak intuitif langsung antara Ulama dengan petani. Tindakan etis dalam Islam diyakini pada puncaknya akan menghasilkan kebahagian dunia dan akhirat.

Ketiga; adanya refleksi mistis. Ulama dan petani di Banten memiliki suat u penilaian identitas Islami yang sangat militan yakni menjadi orang Banten maka wajib hukumnya menjadi orang Muslim. Ketika sudah menjadi Muslim resmi, maka pada praktik kehidupan sehari-hari, mereka akan rajin mengerjakan ritual-ritual dalam Islam seperti mengucapkan dua kalimat syahadat, sholat, zakat, puasa, dan haji.

Dalam konteks ini, sangat dimungkinkan, bahwa para ulama termasuk Syekh Mohammad Arsyad Thawil memanfaatkan tarekat Qadiriyah wa Naqsyabandiyah untuk mendidik golongan petani mengerjakan ibadah bermuatan nilai muhasabah (introspeksi diri) melalui fikr. Di dalam mengerjakan ibadah itu, petani juga didorong untuk melakukan mukasyafah (pembukaan tabir) dengan Tuhannya melalui dzikir. Setelah itu, para petani juga mengerjakan muraqabah (pengawasan diri) dengan Tuhannya melalui suluk. Ketiga proses dalam ibadah ini kemudian membentuk persaudaraan mistis.

\section{Menjadi Orang Minahasa}

Akibat terlibat dalam pemberontakan petani Banten 1888 (Geger Cilegon), Syekh Mohammad Arsyad Thawil diasingkan pemerintah kolonial di penjara Betawi lalu dipindahkan ke Manado. Sebelum tiba di Manado, Syekh Mohammad Arsyad Thawil awalnya berada di Kema, Minahasa. Di masa pertengahan abad ke-19, Kema dijadikan sebagai salah satu alat politik untuk menjalankan perjanjian Belanda-Inggris sebagai bandar bebas. Daerah ini kemudian dijadikan sebagai entrepot menuju Manado dan Maluku di abad ke-19 (Ichsan,2017:56).

Pada 1903, Van Kol berkunjung ke Manado dan menulis pertemuannya dengan narapidana dari Banten di penjara Manado. Di antaranya, Haji Abdul Karim, Haji Muhammad Asnawi, Haji Djafar, Haji Mardjaya, Haji Ramidin, dan Haji Mohammad Arsyad Thawil (Kembuan, 2016). Selepas dari penjara Manado, Syeikh Mohammad Arsyad Thawil akhirnya dipindahkan ke Airmadidi, distrik Tonsea, Minahasa pada usia 37. Selama di Airmadidi, S.M. Arsyad Thawil menjadi tahanan daerah dan gerak geriknya sangat dibatasi. Melalui busana khas haji, S.M, Arsyad Thawil rajin berdakwah dikalangan masyarakat Muslim di Minahasa meskipun mereka tergolong minoritas.

Dia dikenal sebagai ulama yang lebih mengedepankan dialog kultural daripada penghakiman iman. Di daerah ini, dia menikah dengan seorang perempuan Kristen bernama Magdalena Runtu (Tarhimah). Magdalena memiliki seorang anak perempuan bernama Maria (Maryam). Keduanya dijadikan muallaf (Effendi, 1983:19).

Sampai sekarang, belum ada sumbersumber akurat yang menjelaskan tentang keturunan dari istri keduanya ini. Keterangan publik sementara adalah tidak ada pewaris biologis Thawil dari Magdalena. Syekh Mohammad Arsyad Thawil tinggal di Airmadidi kurang lebih selama 46 tahun di tengah Jemaat Kristen Protestan.Pergaulan S.M. Arsyad Thawil dengan Tan Tjien Bie merupakan awal episode dari perjumpaanperjumpaan yang kolaboratif antara Ulama bersama Kapitein Tionghoa. 
Perjumpaan kolaboratif ini merujuk pada relasi pengetahuan dan kuasa selama masa kolonial. Tan Tjien Bie berlatar belakang pengusaha dan resmi diangkat menjadi Kapitein Tionghoa Manado pada 1913 dan berhenti pada 1916 (Kojongian, 2019).

Pada 1912, berdasarkan besluit pemerintah Belanda, Syekh Mohammad Arsyad Thawil diangkat menjadi Penghoeloe Landraad sekaligus bertindak sebagai guru agama Islam di Minahasa (Pinontoan, 2019). Kapitein Tan Tjien Bie sangat terkesan dengan kepribadian Syekh Mohammad Arsyad Thawil. Mereka berkawan dalam semangat kemanusiaan dan Kapitein inilah yang membantu S.M. Arsyad Thawil untuk pindah dari Airmadidi ke Manado. Pinontoan mencatat, sejak di Manado, dia giat melakukan dakwah di bidang pendidikan untuk masyarakat Muslim lokal.

Pada Agustus 1923, Sarekat Islam melaksanakan Nationaal Congres Celebes Manado. Saat itu, Syekh Mohammad Arsyad Thawil bertemu langsung dengan HOS Tjokroaminoto dan kemudian diangkat menjadi Adviseur Hoofd Bestuur Locaal Sarekat Islam Manado.Kongres tersebut dihadiri oleh perwakilan dari Bolaang Mongondow, Gorontalo, Parigi dan Palu. Selain itu, hadir juga Perserikatan Celebes Minahasa, etnis Arab, Cina, dan Jawa. Dalam konteks ini, penulis berargumentasi bahwa Tan Tjien Bie telah berbagi pengetahuan topografi wilayah Muslim dan demografi masyarakat Muslim terhadap Syekh Mohammad Arsyad Thawil. Sehingga, kuasa dakwah dapat tercapai.

Relasi pengetahuan dan kuasa dapat terjalin harmonis, karena sangat dimungkinkan disebabkan dua faktor. Pertama; "kerjasama niaga" di Airmadi di sebagai pusat perdagangan strategis, karena posisinya berada diantara jalur pelabuhan Manado dan pelabuhan Kema pada awal abad ke-20. Sehingga, Airmadidi menjadi tempat persinggahan atau transaksi jual beli. Kebijakan pemerintah kolonial terhadap etnis Arab-China dalam hal izin interaksi niaga di Minahasa juga merupakan alasan mendasar.

Kedua, memori niaga. Ricklefs menemukan bahwa pada pertengahan abad ke17, pelabuhan Banten menjadi jalur perdagangan internasional semua bangsa seperti Persia, India, Siam, Vietnam, Filipina, Jepang dan terutama memberikan akses besar kepada China. Etnis China-Tionghoa pula yang pertama kali memperkenalkan tebu kepada Kerajaan Banten pada 1620-an. Sehingga, daerah itu sejahtera dan makmur (Ricklefs, 2005:181). Jika dilacak pada akhir abad ke-16, sejak armada Cornelis de Houtman mendarat di Banten 1596, mereka terkesima saat menyaksikan komunitas Tionghoa telah mengakar kuat di wilayah tersebut dan memiliki hubungan baik dengan penduduk setempat. Jumlah Tionghoa di Banten pada 1600 diperkirakan telah mencapai sekitar 3000 orang. Selain itu, penting dicatat juga, sebagian besar dari mereka adalah Cina-Muslim. Denys Lombard menyatakan, kaum peranakan Tionghoa memiliki peran besar dalam perkembangan Islam dan nasionalisme Indonesia.

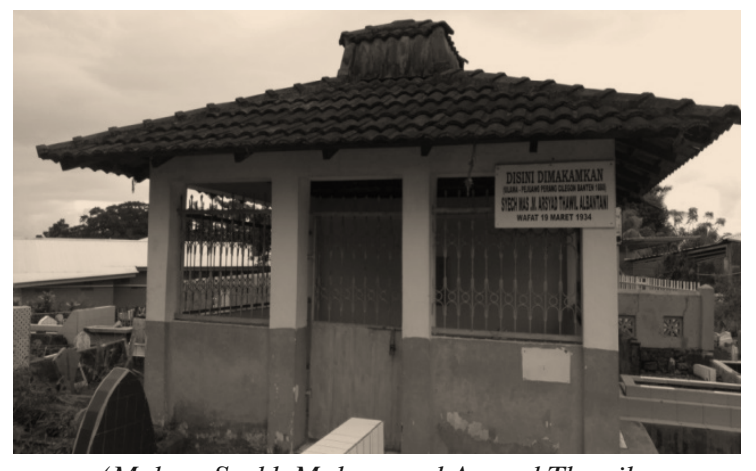

(Makam Syekh Mohammad Arsyad Thawil Sumber: Koleksi Pribadi 2019)

\section{Menghadap Allah Di Kota 1000 Gereja}

Tujuan dari kebijakan pembuangan adalah memutuskan hubungan mereka dengan tempat asalnya. Hal ini disebabkan mereka memiliki pengetahuan dan kuasa untuk menciptakan gerakan perlawanan. Pemerintah kolonial Belanda juga menghendaki sebagaimana disebut Pluvier "The Indies goverment just let inmates die, go insane or be broken". Artinya menjadi gila, kehilangan harapan dan mati perlahan-lahan. Namun, Graffland mencatat;

"Orang-orang buangan itu kehilangan banyak hal walau relatif banyak mengecap kebebasan. Di sini mereka tidak meninggalkan kebiasaan lama (dakwah Islam) dan berusaha untuk hidup sebaik mungkin. Mereka lebih maju dalam hal industri kerajinan dibandingkan kebanyakan orang Minahasa."(Kembuan, 2016). 
Nalar historis dari memori niaga yang telah dijelaskan sebelumnya, sangat dimungkinkan merupakan faktor yang membuat Syekh Mohammad Arsyad Thawil lebih mudah diterima oleh Etnis ChinaTionghoa di Manado. Pada Senin, 19 Maret 1934, Syekh Mohammad Arsyad Thawil, meninggal dunia di Kampung Kumaraka, dalam usia 83 akibat penyakit sesak napas dan sangat dimungkinkan jantung. Kampung Kumaraka terletak di kawasan dataran rendah Tikala, berpenduduk padat, dan dihuni oleh mayoritas Kristen Protestan. Jenazahnya dimakamkan di Pekuburan Islam Lawangirung, Manado, berdampingan makam Gusti Ratu Sekar Kedaton, yang merupakan permaisuri Sri Sultan Hamengkubuwono V. Bagi Jemaat Kristen Minahasa, Syeikh Mohammad Arsyad Thawil adalah Orang Kawanua.

\section{PENUTUP}

Studi ini menunjukkan, peran utama ulama senantiasa terletak pada dimensi pemikiran agama dan pergerakan sosial. Ada tiga doktrin pokok yang dipelajari Syeikh Mohammad Arsyad Thawil di Mekkah, yaitu tauhid, syariah, dan ibadah. Pada kemudian hari, ajaran Islam yang dia dapatkan melalui Syeikh Abdul Gani Bima, Syeikh Ahmad Zaini Dahlan, dan Syeikh Nawawi al-Bantani di Mekkah, ternyata mampu menghadirkan revolusi Banten di Indonesia melalui tiga jaringan: kesadaran eskatologis, tindakan etis, dan refleksi mistis. Snouck mencatat, Mekkah dengan koloni Jawah yang berkembang benarbenar merupakan jantung kehidupan agama kepulauan Hindia Timur yang darinya banyak pembuluh nadi memompakan darah segar dengan kecepatan yang terus meningkat ke seluruh tubuh penduduk Muslim Indonesia (Laffan, 2011:167).

Mayoritas murid-murid dari Syekh Mohammad Arsyad Thawil sekarang banyak tersebar di Perkampungan Komo Luar, Manado. Mereka sudah menjadi warga resmi Sulawesi Utara. Secara umum, mereka masih memakai nama, marga, bahasa, busana, tata krama, dan benda-benda yang berkaitan dengan tradisi Banten dalam kehidupan sehari-hari. Salah satu muridnya yang terkenal, Habib Alwi Bin Abdurrahman Bin Smith, yang memiliki keturunan dari Hadhramaut. Masjid bernama Syekh Mohammad Arsyad Thawil pun berdiri sejak 1932 di perkampungan tersebut.

\section{UCAPAN TERIMA KASIH}

Pertama, penulis mengucapkan terima kasih kepada Nico J.G. Kaptein, Delmus Puneri Salim, Alex John Ulaen dan Nono S.A. Sumampow, yang telah memberikan dorongan, bimbingan, sekaligus arahan sehingga penelitian sejarah ini dapat dilakukan untuk memperluas kajian Islam di Asia Tenggara dan bagi keilmuan yang lebih luas mengenai dunia Muslim. Kedua, penulis mengucapkan terima kasih kepada Institut Agama Islam Negeri (IAIN) Manado yang telah memberikan dukungan dalam bentuk moril dan materil, sehingga penelitian sejarah ini tidak terasa berat. Ketiga, penulis mengucapkan terima kasih kepada Jurnal Redaksi Jurnal Al Qalam Balai Litbang Agama Makassar yang berkenan menerbitkan artikel penelitian sejarah ini, sehingga bisa dibaca oleh masyarakat luas.

\section{DAFTAR PUSTAKA}

Azra, Azyumardi. 2002. Historical Islam: Indonesian Islam in Global and Local Perspective, Bandung: Mizan.

Azra, Azyumardi. 2013. Jaringan Ulama Timur Tengah dan Kepulauan Nusantara Abad XVII \& XVIII, Jakarta: Kencana Press.

Bruinessen, Martin van. 2015. Kitab Kuning, Pesantren dan Tarekat, Yogyakarta: Gading Press.

Burhani, Ahmad Najib. 2016. The Muhammadiyah's Attitude to Javanese Culture in 1912-1930: Appreciation and Tension, Yogyakarta: Suara Muhammadiyah.

Burhanudin, Jajat.2012.Islamic Knowledge, Authority and Political Power: The Ulama in Colonial Indonesia, Bandung: Mizan. 
de Jonge, Christiaan. et.al 2008. How Christianity Obtained A Central Position in Minahasa Culture and Society in Jan Sihar Aritonang and Karel Steenbrink (Editors), A History of Christianity in Indonesia, LeidenBoston:Brill.

Effendi, Yoesoef.1983.Riwayat Hidup Kiyai H. Mas Muchammad Arsyad Thawil,Jakarta : Al-Chasanah.

Fawaid, Achmad. Perjumpaan Etis Dengan Wajah Yang Lain, Jurnal Poetika Vol. I No. 2, Desember 2013.

Gottschalk, Louis. 1985. Understanding History: A Primer of Historical Method, Jakarta: UI Press.

Kembuan, Roger. 2016. Bahagia di Pengasingan: Kehidupan Sosial Budaya Masyarakat Buangan di Kampung Jawa Tondano, Tesis Universitas Gadjah Mada.http://etd.repository.ugm.ac.id/

Kojongian, Adrianus. 2019.Kapitein Tionghoa di Manado. adrianuskojongian.com

Kuntowijoyo, 2008. Historical Explanation, Yogyakarta : Tiara Wacana.

Laffan, Michael. 2011. The Makings of Indonesian Islam, Princeton: Princeton University Press.

Laffan, Michael.2003.Islamic Nationhood and Colonial Indonesia: The Umma Below the Winds, London: Routledge.

Langlois \& Seignobos, 2015. Introduction to The Study of History, Yogyakarta: Indoliterasi.

Martin, Richard C. (Ed). 2002. Approaches to Islam in Religious Studies, Surakarta: Muhammadiyah University Press.

Nasution, Harun (Ed). 1992. Ensiklopedi Islam Indonesia,Jakarta: Djambatan Press.
Niam, Khoirun. The Discourse of Muslim Intellectuals and Ulama in Indonesia : A Historical Overview, Journal of Indonesian Islam, Vol 04, No 02, December 2010.

Nur Ichsan A. Muhammad, 2017. Pelabuhan Kema dan Jaringan Muslim Nusantara Abad XX, Laporan Penelitian Balai Pelestarian Nilai Budaya Sulawesi Utara.

Pinontoan, Denni H.R. 2019. Syekh Mas Mohammad Arsyad Thawil: Hadji Banten di Manado. www.katanisme.com.

Reid, Anthony. 2004. Sejarah Modern Awal Asia Tenggara, Jakarta: LP3ES.

Ricklefs, M.C. 2005.Sejarah Indonesia Modern 1200-2004, Jakarta: Serambi Press.

Steenbrink, Karel. 2017. Dutch Colonialism and Islam in Indonesia: Conflict and Contact 1596-1950, Yogyakarta: Gading Press.

Stockdale, John Josep. 2017. The Island of Java,Yogyakarta: Indoliterasi.

Thorn, William. 1815. Memoirs of The Conquest of Java: With The Subsequent Operations of British Forces in The Oriental Archipelago, London: White Hall.

Vlekke, Bernard H.M. 2016. Nusantara: A History of Indonesia, Jakarta: Gramedia Press.

Weber, Max. 2012. Sosiologi Agama: A Handbook, Yogyakarta: IRCiSoD.

Weichart, Gabriele. 2004. Identitas Minahasa, Jurnal Antropologi Indonesia Vol.74. 
